\section{Коллаборация как источник трансформации бизнес-моделей}

Н.А. КОРОльковА, генеральный директор ЗАО «Консалтинговый центр «ЛАРИУМ", Москва. E-mail: korolkovana@lariums.com

E.C. ВАСЮТИНА, кандидат экономических наук, Российский

государственный социальный университет, Москва. E-mail: esvas@mail.ru

В статье рассматривается влияние коллаборации на развитие различных систем организации деятельности. Основой исследования послужил обзор практик реализации коллабораций с акцентом на изменения бизнес-моделей в различных предметных областях при сопоставлении мирового и российского опыта. Основными результатами анализа являются определение сущности бизнесмоделей новой формации, выявление причин создания и системообразующих условий функционирования коллабораций. Дана оценка ключевых элементов, обеспечивающих одновременно устойчивость и возможность расширенного развития системы, построенной на базе коллаборативного подхода. Изложен развития системы, построенной на базе коллаборативного подхода. Изложен авторский взгляд на формирование основных тенденций. В заключении поставКлючевые слова: коллаборация, коллаборативный проект, бизнес-модель, сотрудничество, стратегия win-win, сетевая модель, принцип вовлеченности, принцип совмещенности

Коллаборация - процесс, на сегодняшний день не имеющий как четкого определения (или общесистемной интерпретации), так и принятой классификации подходов к его формированию и развитию. Однако он заставляет обратить на себя внимание, так как все чаще начинает фигурировать при построении (моделировании) бизнес-процессов различных сложных систем. Опираясь на исторический анализ становления указанного процесса в различных отраслях и сферах деятельности, а также практический опыт по стратегическому планированию, попытаемся выстроить системное видение этой проблемной области.

Зарождение и наибольшее развитие данная форма сотрудничества получила в модной индустрии, где формируются коллаборации брендов. Далее по масштабам применения следуют сетевые коллаборации ученых в сфере научных исследований и опытноконструкторских разработок. Особого внимания заслуживает IT-индустрия, в которой проходят становление коллаборации вендоров. Формируются также заделы распространения исследуемого процесса в других отраслях, например, в образовании. Сфокусируем свое внимание на выявлении особенностей соответствующих бизнес-моделей или их элементов.

\section{Коллаборация брендов в модной индустрии}

Термин «коллаборация» уже довольно давно и широко применяется в брендинге модной индустрии, где первый описанный случай так называемой «капсульной коллекции» зафиксирован в 1969 г. Уже к 2004 г. устоялся термин «культура коллаборации», который означает совокупность достижений в этой области и раскрывает систему взаимоотношений между масс-маркетами и известными дизайнерами, а коллаборационные проекты как таковые являются одним из самых эффективных вариантов маркетинговых стратегий на сегодняшний день.

Мировой опыт таких коллабораций насчитывает более 1000 примеров. В настоящее время развитие процесса находится на стадии масштабирования международной формы сотрудничества. Проиллюстрируем различные форматы реализации коллаборативных проектов на нескольких ярких примерах из мировой практики.

Капсульные коллекиии шведского масс-маркетингового бренда H\&M с люксовыми брендами (ежегодно с 2004 г.). Коллекция 2015 г. Н\&M с французским брендом Balmain вошла в число лучших мировых практик, а также является наиболее эффективной, как показала финансовая отчетность Н\&М по итогам 2015 г. ${ }^{1}$ В частности, коллекция отмечена как один из факторов увеличения продаж Н\&M на 19\%, валовой прибыли - на 16\%. При этом акцент сделан на имиджевой составляющей эффективности, так как продажи самой капсульной коллекции составляют не более $1 \%$ от годового оборота.

Регулярная линия спортивной одежды американской компании Nike и Национальной баскетбольной ассоциации (NBA): партнерство анонсировано в июне 2017 г. на сезон 2017-2018 гг. и основывается на внедрении цифровых технологий в сегменте спортивной одежды (джерси и экипировка для NBA). С одной стороны, Nike становится техническим спонсором лиги NBA, с другой - начинается продажа баскетбольных маек, в которых

Данные консолидированной финансовой отчетности Н\&М за 2015 год.[Эл. реcypc].URL: http://about.hm.com/en/investors/reports.html (дата обращения: 06.11.2017). 2 Пресс-релиз от 15.09.2017 - данные официальной пресс-службы Nike, INC [Эл. pecypc]. URL: https://news.nike.com/news/how-nba-uniform-is-made (дата обращения: 06.11.2017). 
использована новая технология NikeConnect ${ }^{3}$. Вшитый в одежду NFC-чип запускает посредством беспроводной связи приложение для смартфона NikeConnect. Взаимодействие с NikeConnect напрямую зависит от клубной принадлежности майки (Chicago Bulls, Lakers, Celtics и т.п.): пользователь получает информацию об игроках, ближайших играх и спецпредложениях от команды. В перспективе NikeConnect предполагает стать эксклюзивной платформой, поддерживающей активные инструменты: от взаимодействия с болельщиками до полноценных программ лояльности.

Именной бренд Air Jordan - результат коллаборации американской компании Nike и легендарного баскетболиста Майкла Джордана, начатой еще в 1984 г. Основной акцент производства высококачественная дорогая баскетбольная обувь и одежда. Пик развития коллаборации пришелся на начало 1990-х годов-доходы от продаж Nike выросли с 870 млн до 4 млрд долл. США за 1993 г. Теперь бренд входит в число трех основных категорий продукции Nike, наравне с Sportswear и Running, обеспечившими прирост доходности на уровне 8\% в 2017 г. (выше среднеотраслевого) ${ }^{4}$.

Российский опыт в рассматриваемой сфере более скромный и берет свое начало с 2000-х годов. Среди коллабораций на российском рынке можно выделить следующие:

- регулярная линия Adidas Originals by GJO.E: первая в истории немецкого бренда коллаборация с российским дизайнером Grunge John Orchestra;

- капсульная коллекция российского производителя обуви и аксессуаров «Эконика» и эксперта моды Эвелины Хромченко, основанная на авторской формуле «25 модных инвестиций в гардероб». Рентабельность по проектам коллаборации оценивается на уровне $15-20 \%$, это выше общего уровня рентабельности компании [Саркисов, 2016]. Успешность проекта также подтверждается пролонгацией сотрудничества с 2016 г. по настоящее время (коллекция 2017-2018 гг. не станет последней);

- капсульная коллекция финского бренда Finn Flare и российского дизайнера Игоря Чапурина, разработанная специально для

${ }^{3}$ Пресс-релиз от 15.09.2017 - данные официальной пресс-службы Nike, INC [Эл. pecypc]. URL: https://news.nike.com/news/nikeconnect-jersey-app-guide (дата обращения: 06.11.2017).

${ }^{4}$ Данные консолидированной финансовой отчетности Nike, INC за 2017 год (4-й квартал и весь год) [Эл. pecypc]. URL: https://goo.gl/NvXUqa (дата обращения: 06.11.2017).
России (три проекта в течение 2017 г.), основана на совпадении взглядов по ключевым производственным критериям, а также едином понимании обеих сторон тенденций в сегменте (взаимодействие в иных формах идет с 2015 г.).

В целом для российского рынка характерны доминирование формата «капсульных коллекций», четкая локация на территории страны (нет выхода даже на географический охват СНГ), эпизодичность взаимодействия с международными брендами, что объясняется слабой развитостью национального рынка (международные бренды не готовы к равноправному сотрудничеству и ограничиваются взаимодействием с медийными личностями в России для дополнительного активного продвижения продукции внутри страны).

Однако интересен тот факт, что отношения в российской модной индустрии начинают приобретать межотраслевой характер. В качестве примера можно привести коллаборации ювелирной компании LeDiLe - капсульные коллекции ювелирных украшений: «Кружевная вьюга» с брендом «Оренбургские пуховые платки», «Павловопосадские узоры» с Павловопосадской платочной мануфактурой 5 . Результаты сотрудничества предварительно оценены как положительные, количественная оценка эффективности коллаборации будет отражена в финансовой отчетности компаний по итогам 2017 г.

Эффективность реализации подобных проектов в России основывается на результатах оценки потребительского выбора в данной и смежных отраслях ${ }^{6}$ :

- 57\% компаний, занимающихся косметикой и модой, используют лидеров мнений в рамках своих маркетинговых стратегий;

- 71\% потребителей совершают покупку на основе рекомендации в социальных сетях и только 20\% доверяют прямой рекламе;

- 70\% подписчиков YouTube (русскоязычного сегмента) доверяют советам знаменитостей, при этом сервис признан одним из основных каналов продвижения продукции.

С точки зрения практики формирования бизнес-моделей интересно, что за последнее десятилетие в модной индустрии сложились некие неформальные нормы и правила по созданию коллаборационных линеек, которые легли в основу формирования двух ключевых подходов к организации деятельности. Это либо

\footnotetext{
${ }^{5}$ URL: https://goo.gl/K7VDPc (дата обращения: 30.10.2017).

6 Данные официального сайта проекта «LabelUp» [Эл. pecypc]. URL: https://labelup. $\mathrm{ru} /$ (дата обращения: 30.10.2017).
} 
короткая, ограниченная во времени маркетинговая акция, так называемая flash-продажа, либо регулярная линия - капсульная коллекция или отдельная модель, которая встроена в общую сезонную коллекцию и продается весь сезон. Таким образом, если представлять это в общем виде без отраслевой специфики, то прослеживаются основные элементы бизнес-моделит:

- ключевой партнер: известный бренд / медийная личность / «лидер мнений»;

- ключевой процесс: маркетинговая акция / капсульная коллекция;

- ключевые ресурсы: использование ограниченного по времени действия процессов, при этом действует принцип объединения ресурсов ключевых партнеров (снижение затрат на продвижение, обмен технологиями производства и т.п.);

- ценностное предложение: создание имиджевого продукта, который призван продвигать популярность основного ассортимента;

- новая технология клиентских отношений: форма маркетинговой активности, которая позволяет обойти барьеры восприятия потенциального потребителя и сформировать его заинтересованность (и даже более высокую потребительскую ценность).

При этом важно подчеркнуть, что привлекательность отдельной коллаборации для потребителей напрямую зависит от популярности обеих сторон сотрудничества, заинтересованность которых очевидна и проявляется как в коммерческой составляющей (увеличение нормы прибыли), так и в имиджевой (поднятие статуса). Системообразующее условие отношений - рациональный выбор партнёра с позиции эффективности сотрудничества. Далее при проектировании коллаборации необходимо всегда учитывать: сопоставимость масштабов потребительских баз потенциальных партнеров и общность целевой аудитории обоих брендов.

Уже не первый год в ноябре-декабре информационно-аналитические издания модной индустрии формируют «рейтинги коллабораций года», в которых представлены наиболее эффективные примеры сотрудничества. При этом интересно следить за изменениями в качестве этого сотрудничества: если раньше оно опиралась на уже устоявшиеся долгосрочные партнерские отношения, то сейчас все чаще коллаборацию выстраивают противоборствующие бренды, ранее слывшие непримиримыми конкурентами. Пока еще рано говорить о тенденции, однако подобное наблюдение характерно и для других отраслей.

${ }^{7}$ При описании элементов бизнес-модели авторы отталкивались от классического инструментария «Канвас» (от англ. Business model canvas), предложенного Александром Остервальдером и Ив Пинье.

\section{Научные коллаборации (сетевая коллаборация ученых)}

Формирование научных коллабораций уже выделяется как одна из сложившихся тенденций развития научно-технической сферы [Богатов, Сыроежкина, 2016], при этом можно выделить как явные, так и скрытые причины их появления. В частности, явной причиной является необходимость и целесообразность обмена опытом и научной инфраструктурой. Ранее (до конца XX века) многие потенциально эффективные коллаборации так и не были сформированы или были ограничены в своем развитии из соображений секретности в целях обеспечения национальной безопасности. Однако в последние годы ситуация начала коренным образом меняться: научные исследования и опытно-конструкторские разработки, которые в последующем становятся основой для инноваций, с каждым годом дорожают. Отдельные страны, даже с высоким уровнем инвестиционных возможностей, не всегда могут в полной мере обеспечить финансирование отдельных значимых проектов и вынуждены проявлять открытость к взаимовыгодному сотрудничеству со «вчерашними конкурентами» - это и является скрытой причиной формирования научных коллабораций.

Таким образом, масштабные научные проекты реализуются в сотрудничестве научных коллективов из разных стран и, соответственно, при совместном финансировании. В настоящее время уже можно говорить о формировании ряда бизнес-моделей научных коллабораций. Для выявления их особенностей, а также общих черт с коллаборациями в прочих сферах деятельности рассмотрим несколько примеров.

Одной из крупнейших международных научных коллаборащий является LSC (Laser Interferometer Gravitational-Wave Observatory (LIGO) Scientific Collaboration), основанная в 1997 г. и занимающаяся изучением гравитационных волн как следствия наиболее значимых событий (изменений) во Вселенной. В настоящее время коллаборация насчитывает свыше 1000 ученых из более чем 100 учреждений 18 стран мира $^{8}$. В ее составе работают и две научные группы из России: группа В.П. Митрофанова (кафедра физики колебаний физического факультета МГУ, Москва) и группа

${ }^{8}$ Данные официального сайта LSC [Эл. pecypc]. URL: http://ligo.org/about.php (дата обращения: 25.11.2017). 
академика РАН А.М. Сергеева (Институт прикладной физики РАН, Нижний Новгород). Учреждения, заинтересованные в присоединении к LSC, рассматриваются как потенциальные члены и должны подписать Меморандум о взаимопонимании как с самой научной коллаборацией, так и с Лабораторией LIGO, после чего необходимо представить предлагаемую совместную программу на заседании LSC. Новое членство утверждается большинством в две трети голосов Совета LSC.

Этот пример иллюстрирует два важных организационных аспекта, характерные для большинства эффективных бизнесмоделей научных коллабораций:

- научные коллаборации не предполагают жестких договорных отношений, а реализуются на основе более гибких форм - юридических соглашений (меморандума о взаимопонимании);

- решения в рамках коллаборации принимаются коллегиально, но при действии единого центра принятия управленческих решений.

Появился прецедент реализации возможности межколлаборативного проекта: коллаборации LIGO и Virgo, ранее бывшие негласными конкурентами, договорились о совместной обработке данных своих детекторов с февраля 2016 г. Причиной объединения стало торможение в развитии проектов, вынудившее их объединить усилия для достижения научных результатов. Это заставляет обратить внимание на вопросы стратегического планирования взаимоотношений в научной сфере, а именно, на переход к стратегии обоюдного выигрыша (англ. win-win) [Кудашкина, 2003]. В настоящее время подход подавления конкурентов в научно-технологической сфере считается малоэффективным.

Наибольшего развития в становлении научных коллабораций достиг CERN, который, будучи изначально сам коллаборативным проектом, к настоящему времени стал своеобразной платформой для возникновения коллабораций в различных областях ядерных исследований. Официальной статистической информации по количеству организованных и действующих коллабораций CERN нет, однако проведенный контент-анализ позволил выявить более 10 успешных проектов, в том числе NA61/SHINE и NA49, а также CMS и ATLAS. При этом негласно соглашение о сотрудничестве с CERN является основой для уставных документов производных коллабораций. Таким образом, происходит масштабирование бизнес-модели CERN, что в основе своей отдаленно напоминает процесс франчайзинга.
Научные коллаборации могут быть как международными, так и национальными. Возьмем, к примеру, национальную коллаборацию Великобритании в области клинических исследований (UK Clinical Research Collaboration (UKCRC)). Сообщество создано в 2004 г. в целях реорганизации клинической исследовательской среды в Великобритании, а также повышения уровня национального здоровья и благосостояния. Особенностью данной научной коллаборации является лежащий в ее основе принцип вовлеченности: в UKCRC сложные долгосрочные проблемы решаются всеми ключевыми заинтересованными сторонами, в том числе пациентами, которые работают вместе с научными учреждениями, а также ведущими клиниками страны и Национальной службой здравоохранения.

Таким образом, если ранее научные коллаборации можно было охарактеризовать как сетевое организационное хозяйственное объединение двух и более автономных субъектов (государств, частных организаций и отдельных ученых) для взаимодействия в реализации основного и вспомогательных проектов [Коробкина, Омельченко, 2017], то сегодня с учетом общности обеспечения такого сотрудничества наиболее адекватным определением сущности научной коллаборации можно считать следующее: организованное, преимущественно в сетевой форме, сообщество равноправных представителей научного сектора, бизнес-структур и государственной власти (различных организаций и стран), созданное с иелью достижения общего качественного результата в определенной научной сфере в условиях совместного обеспечения деятельности (информачионного, технологического, финансового и т.n.) и общности зоньи интересов.

В контексте выявления особенностей трансформации бизнесмоделей научных коллабораций и их элементов можно подчеркнуть следующее:

- в основе их организации лежит стратегия win-win;

- при условиях масштабности проектов наиболее эффективной является сетевая форма организации сотрудничества;

- формой закрепления основных аспектов организации взаимоотношений, альтернативной договору, может быть соглашение о взаимопонимании;

- у коллаборации должен быть оператор, т.е. единый центр принятия управленческих решений, при существовании 
контролирующего звена - другого (самостоятельного) элемента организационной структуры, например, наблюдательного совета;

- коллаборация может формироваться вокруг организации одного проекта, но при этом им не ограничивается: ее жизненный цикл существенно шире и определяется развитием зоны общих интересов.

\section{Коллаборация вендоров в IT-индустрии}

Коллаборативные тенденции в данной области проявляются наиболее многогранно:

- коллаборативные проекты как форма сотрудничества вендоров (аналог научных коллабораций, но ориентированный на разработку программного обеспечения);

- коллаборация как организация профильных сообществ;

- коллаборация как исходный принцип для построения различных алгоритмов и проектирования информационных систем в целом (семейство алгоритмов коллаборативной фильтрации, алгоритмы совместного поиска информации (Collaborative Information Seeking, CIS) и т.п.).

В рамках решения поставленных в статье задач рассмотрим только два первые случая.

Коллаборативных проектов множество, и реализуются они в различных секторах - от цифровой дистрибьюции до комплексной разработки сложного программного обеспечения и даже цифровых платформ. С позиции международного опыта интересен процесс становления коллаборации вендоров NorduGrid (Североевропейская модель рассредоточенных вычислений и обработки данных). Данная коллаборация координирует разработку и обеспечивает поддержку свободно распространяемого связующего программного обеспечения с открытым кодом для grid-инфраструктур, известного под названием Advanced Resource Connector (ARC). Коллаборация объединяет научно-исследовательские группы и проекты из Венгрии, Дании, Литвы, Норвегии, Словакии, Словении, Украины, Финляндии и Швеции, базируясь на меморандуме о взаимопонимании. Как видим, основы бизнес-модели схожи с выявленными при обзоре научных коллабораций.

Другой пример из российской практики - коллаборация Advantech и Kaspersky Lab, которая реализует свою деятельность в области безопасности промышленной ИТ-инфраструктуры, связанной с развитием «интернета вещей». В этом случае необходимо обратить внимание на статус проекта: он развивается в рамках сразу двух базовых направлений государственной программы «Цифровая экономика» ${ }^{9}$ и потенциально является одним из флагманских для развития российской IT-индустрии в целом. Таким образом, модель коллаборации является более привлекательной по сравнению с организацией консорциума, совместного предприятия или каких-либо иных форм жестких договорных отношений.

Одной из ярких тенденций в ІТ-индустрии стало создание профильных сообществ. В основном они развиваются вокруг какой-нибудь технологии или языка программирования, но бывают и более широкопрофильные сообщества, к числу которых относится, к примеру, GitHub - один из крупнейших веб-сервисов для хостинга IТ-проектов и их совместной разработки. Фактически он представляет собой коллаборативную платформу. Его позиционирование основывается на принципе «социальной сети для разработчиков». Среди функционала сервиса ${ }^{10}$, кроме непосредственно размещения кода, реализованы возможности общения участников с комментированием правок друг друга, мониторинг новостей «знакомых», а также объединение своих репозиториев. GitHub предлагает удобный интерфейс для этого и может отображать вклад каждого участника в виде дерева. Тем самым создана институциональная среда для наиболее эффективной работы программистов.

K классическому узкопрофильному относится R-сообщество, развитие которого фокусируется на языке программирования R. Оно обладает своей культурой и включает в себя как разработчиков, так и пользователей различных уровней.

Тем самым коллаборация в IT-сфере становится одной из наиболее эффективных моделей организации, способствующих быстрому развитию отрасли в целом. При этом ее отличительной особенностью является то, что сотрудничество широкое, а не сфокусированное на решении узкого круга задач. Системы, строящиеся по этой модели, можно отнести к категории самоорганизованных,

Распоряжение Правительства РФ от 28.07.2017 № 1632-р «Об утверждении программы «Цифровая экономика Российской Федерации»».

${ }^{10}$ Инструкции по работе с возможностями GitHud [Эл.pecypc]. URL: https://guides. github.com/ (дата обращения: 26.11.2017). 
то есть не требующих прямого управленческого воздействия: все решает созданная институциональная среда.

\section{Коллаборативные платформы в сфере образования}

В сфере образования существуют прецеденты выстраивания так называемых «коллаборативных платформ», которые отражают новую образовательную модель в виде дерева - нелинейно связанных друг с другом материалов с возможностью ранжирования пользовательского контента. Одним из ярких примеров является проект Rosalind - платформа для изучения биоинформатики посредством совместного решения проблем (прикладных задач). Особо интересно отметить, что это совместный проект Калифорнийского университета в Сан-Диего, Санкт-Петербургского академического университета, Российской академии наук и агентства Crowderry. Он реализует альтернативный подход в противовес платформам онлайн-образования, таким как Coursera или Udacity, которые не предназначены для сложных программных заданий в области Data Science, а также являются менее гибкими по причине прямой связи с офлайн-курсами университетов. О перспективах и преимуществах такого подхода свидетельствует и тот факт, что в 2013 г. другая коллаборативная платформа MindMixer во время курса TechniCity заменила традиционные форумы на Coursera: участники обсуждали насущные вопросы виртуального города.

Таким образом, коллаборативную платформу можно охарактеризовать как вариант реинжиниринга наиболее распространенной на сегодня модели MOOC (англ. Massive open online courses, рус. Массовый открытый онлайн-курс). Со слов основателя проекта Rosalind ${ }^{11}$, ключевая идея трансформации концепта состоит в том, чтобы образование строилось не на отдельных личностях: представители профессорско-преподавательского состава могут дать старт какой-то области, а затем сообщество подхватывает, оптимизирует и дополняет материал. Центральным при этом является вопрос критерия формирования сообщества. Для решения этой задачи предлагается использовать «модель

${ }^{11}$ Чеботарь Н. Коллаборативная платформа-и есть будущее образования: интервью с основателем проекта проекта Rosalind Николаем Вяххи [Эл. ресурс]. URL: https:// goo.gl/Gi4Y1u (дата обращения: 30.10.2017). привилегий» для тех, кто становится экспертом в определенной области, то есть добавлять и курировать материал может только тот субъект, который показал успешное освоение (прохождение) всех имеющихся заданий в данной области. Таким образом, раскрывается еще один основной принцип модели, назовем его принцип «совмещенности»: вокруг предмета (дисциплины, курca, области знаний) будет образовываться круг людей, которые одновременно и учатся, и учат.

\section{Инфраструктура для коллабораций}

Необходимо также отметить, что начала появляться платформа для коллабораций, то есть определенные обслуживающие структуры (сервисы, организации), обеспечивающие возможности создания и функционирования коллабораций в различных сферах деятельности. Это своего рода среда или площадка, где могут «встретиться» субъекты, желающие организовать коллаборацию, подобрать партнера и запустить проект. Платформы могут быть как специализированными (под 1-2 смежные сферы деятельности), так и многопрофильными (без ограничений по сферам). В качестве примеров перечислим лишь некоторые из них.

Платформа LabelUp ${ }^{12}$ - российская платформа для создания коллабораций в форме эффективных кампаний в социальных сетях. Основными акторами взаимодействия выступают блогеры и бренды.

Платформа для коллаборации бизнеса и блогера ${ }^{13}$ : функционирует как отдельный локализованный проект на территории Украины, однако его развитие поддерживается представителями международного инвестиционного сообщества посредством реализации модели краудфандинга, что, кстати, само по себе есть проявление коллаборации. При этом результаты мониторинга краудфандинговых площадок подтверждают факт начала формирования данной инфраструктурной прослойки.

Проект MindMixer - платформа для создания «местных сообществ», то есть коллабораций для организации совместных решений конкретных задач (реализации конкретных проектов) независимо от их сложности. Эффективность платформы можно

\footnotetext{
${ }^{12}$ URL: https://goo.gl/K7VDPc (дата обращения: 30.10.2017).

13 Данные официального сайта инвестиционной платформы Startup.Network [Эл. pecypc]. URL: https://startup.ua/startups/337248.html (дата обращения: 30.10.2017).
} 
оценить достижением следующих результатов: сформировано 1200 сообществ; число участников платформы достигло 1,2 млн чел.; в разработке находятся 50 тыс. проблемных вопросов, заявленных именно со стороны участников платформы ${ }^{14}$.

Проект MySidewalk ${ }^{15}$ - платформа, позволяющая обмениваться мыслями, выставлять идеи на голосование и узнавать о новых городских проектах (от создателей MindMixer, близкая по смыслу).

\section{Заключение}

Таким образом, в статье было последовательно выявлено множество основных черт бизнес-моделей, отталкивающихся в своем построении и развитии от коллаборации. Вместе с этим анализ указывает на ряд вопросов, требующих проработки, в том числе:

- очевидно, что не каждое сотрудничество можно отнести к коллаборации, следовательно, целесообразно определить критерии отнесения к данной форме;

- подчёркнуто, что для эффективного взаимодействия в формате коллаборации необходимо создание и развитие особой институциональной среды - это актуализует вопрос комплексного описания данной среды и особенностей ее построения;

- интересно выявление специфики реализации коллаборативных проектов в рамках корпоративного и государственного секторов;

- необходимо внимание к блоку вопросов, связанных с масштабированием моделей коллабораций;

- актуализируется вопрос оценки целесообразности перехода к коллаборации как на внутреннем (форма внутрикорпоративного взаимодействия), так и внешнем (форма сотрудничества контрагентов) контурах организаций, а также оценки эффективности подобных управленческих решений и т.п.

Ответы на эти и многие другие вопросы еще предстоит найти по мере увеличения числа исследований в этой области и развития самой практики реализации коллаборативных проектов. Сегодня коллаборация относится к процессам, которые только начинают основной виток своего развития. В этой связи он еще

${ }^{14}$ Данные официального сайта проекта MindMixer [Эл. pecypc]. URL: https://www. mindmixer.com/ (дата обращения: 30.10.2017).

${ }_{15}^{15}$ Официальный сайт проекта MySidewalk [Эл. ресурс]. URL: http://app.mysidewalk. com/ (дата обращения: 30.10.2017). долгое время будет малоизученным, несмотря на повышение интереса к нему со стороны научного и экспертного сообществ.

\section{Литература}

Саркисов С. Доклад на XII ежегодной конференции «Ритейл в России», 14.09.2016, Москва.

Богатов В.В., Сыроежкина Д.С. Коллаборация научных организаций как элемент инфраструктуры науки // Наука. Инновации. Образование. № 4(22). 2016. С. 30-44.

Кудашкина Е. Личная эффективность: правило win-win // Ведомости. 2003. 5 июня. [Эл. ресурс]. URL: https://goo.gl/gbtaJD (дата обращения: 12.11.2017).

Коробкина Ю.Ш., Омельченко А.М. Научные коллаборации: определение, классификации и характеристики // Экономика: вчера, сегодня, завтра. 2017. Т. 7. № 4А. С. 72-83.

Статья поступила 12.12.2017.

\section{Summary}

Korolkova N.A., Consulting Center LARIUM (CJSC),Vasiutina E.S., Department of economic theory and international economic relations, Russian State Social University

Collaboration as a Source of Business Model Transformation

In article influence of collaboration on development of different systems of the organization of activities is discussed. A research basis, the review the practicain of implementation of collaborations taking into account focus on changes of business models in different activity domains by comparison of international and Russian experience served. The main analysis results are determination of an entity of business models of a new formation, detection of the reasons of creation and backbone operating conditions of collaborations. An assessment of the key elements providing simultaneously stability and a possibility of expanded development of the system constructed on the basis of collaborative approach is given. The author's opinion is stated of formation of the main tendencies. In the inference, relevant questions for continuation of perspective researches is raised

Collaboration; collaborative project; business model; cooperation; win-win strategy; network model; principle of involvement; principle of combination activity

\section{References}

Sarkisov S. (2016) Doklad na XII ezhegodnoj konferencii «Ritejl v Rossii», 14.09, Moskow.

Bogatov V.V., Syroezhkina D. S. (2016)Kollaboracija nauchnyh organizacij kak jelement infrastruktury nauki. Nauka. Innovacii. Obrazovanie.[Science.Innovation Education] No. 4(22). Pp. 30-44.

Kudashkina E. (2003) Lichnaja jeffektivnost': pravilo winwin. Vedomosti. 5 ijunja.Available at: https://goo.gl/gbtaJD (accessed 12.11.2017).

Korobkina Ju.Sh., Omel'chenko A. M. (2017) Nauchnye kollaboracii: opredelenie, klassifikacii i harakteristiki. Jekonomika: vchera, segodnja, zavtra. [Economics. Yesterday,Today and Tomorrow] T. 7. No. 4A. Pp. 72-83. 